\title{
PERANCANGAN ALAT PEMIPIH SEMI MEKANIS UNTUK BIJI MELINJO
}

(Desingn a mechanical slaker spring for its melinjo)

\author{
Agus Rizal Fiki ${ }^{1}$, Mustaqimah ${ }^{1}$, Diswandi Nurba ${ }^{1 *}$ \\ ${ }^{1}$ Program Studi Peternakan, Fakultas Pertanian, Universitas Syiah Kuala
}

\begin{abstract}
Abstrak. Tanaman melinjo adalah tanaman yang tumbuh baik pada daerah tropis, salah satunya adalah Indonesia. Produk olahan melinjo adalah emping melinjo, emping melinjo sejenis kripik yang dibuat dari biji melinjo tua dan merupakan salah satu komoditi pertanian yang memiliki harga tinggi. Selama ini proses pembentukan emping melinjo masih menggunakan cara-cara sederhana yaitu dengan cara memukul. Perancangan alat pemipih adalah untuk membantu masyarakat dalam memproduksi emping melinjo dalam upaya untuk meningkatkan hasil produksi emping. Dari hasil pengujian yang dilakukan dengan menggunakan alat rancangan didapatkan waktu rata-rata 0,51 menit dengan kapasitas pemipih yang dapat menghasilkan emping melinjo rata-rata 15,914 gr. Sedangkan pemipih secara tradisional didapatkan rata-rata waktu 1,04 menit dengan kapasitas kerja tradisional didapatkan hasil pemipih 7,820 gr. Untuk memipih 5 biji melinjo dengan 3 kali ulangan pukulan keseragaman hasil yang bagus terdapat pada alat rancangan dengan ketebalan $0,95 \mathrm{~mm}$ dan diameter $3,45 \mathrm{~cm}$, sedangkan pada alat pemipih tradisional terdapat nilai ketebalan $0,72 \mathrm{~mm}$ dengan diameter emping $3,65 \mathrm{~cm}$. kehilangan hasil merupakan kehilangan kadar air yang dapat menurunkan berat awal biji menlinjo menjadi berat akhir emping. Kehilangan pada alat rancangan semi mekanis 39,41\% dengan berat awal yang diratakan 8,105 gr dan pada alat tradisional $39,38 \%$ dengan berat yang telah diratakan 8,133 gr.
\end{abstract}

Kata kunci : Biji melinjo, Pemipih, Rancang Alat semi mekanis

Abstrak. Melinjo is a plant which grow at the tropics, one of them is Indonesia. The product from this melinjo is melinjo chips. Melinjo chips is a kind of chips made from old melinjo seed and is one of agricultural commodity which have a high price. So far to make the melinjo chips still using a simple way which is by mashing the gnetum gnemon seed. Designing a mashing instrument is an effort to improve the production of melinjo chips to help communities increasing melinjo chips products. From the tests carried out by using this design instrument obtained the average time is 51 seconds with average mashing work capacity 15,914 grams. While mashing in traditional way obtained the average time is 1 minutes 04 seconds with average traditional way work capacity 7,820 grams. To mashing 5 melinjo seed in 3 repetition the better mashing uniformity result is on the mashing instrument with $0,95 \mathrm{~mm}$ thickness and $3,45 \mathrm{~cm}$ diameters, while in traditional way obtained $0,72 \mathrm{~mm}$ thickness with 3,65 diameters. The lost result is cause by the lose of water level which can lower initial melinjo seed weight. The lost in this mashing semi-mechanic instrument is 39,41\% with 8,105 grams average initial weight while in traditional mashing way is $39,38 \%$ with 8,133 grams average initial weight

Keywords : Melinjo seeds, flekes, semi-mechanical tool desingn

\section{PENDAHULUAN}

Tanaman melinjo adalah tanaman yang tumbuh baik pada daerah tropis, salah satunya adalah Indonesia. Hampir semua daerah di Indonesia dapat ditumbuhi tanaman melinjo, akan tetapi tidak semua daerah dapat menghasilkan melinjo secara optimal. Salah satu daerah yang dapat ditumbuhi melinjo adalah Provinsi Aceh. Daerah yang membudidayakan tanaman melinjo di Aceh ialah kabupaten Pidie, tanaman melinjo yang dibudidayakan di Kabupaten Pidie telah tercatat pada tahun 2014 banyaknya tanaman yang dibudidayakan 384,188 batang, BPS, 2014. Salah satu produk olahan melinjo adalah emping melinjo. Emping melinjo sejenis kripik yang dibuat dari biji melinjo tua dan merupakan salah satu komoditi pertanian yang memiliki harga tinggi, makanan ini banyak diproduksi oleh industri skala kecil tetapi masih dalam pengolahan secara tradisional.

Dalam usaha pengembangan emping melinjo, alat adalah sebagai unsur utama untuk mengolah bahan dalam jumlah yang banyak. Perancangan adalah proses menuangkan ide dan gagasan berdasarkan teori-teori dasar yang mendukung. Perancangan alat pemipih adalah untuk membantu masyarakat dalam memproduksi emping melinjo upaya untuk meningkatkan hasil 
produksi emping. Alat pemipih yang dirancang mempunyai kegunaan untuk memipihkan biji melinjo yang masih utuh hingga menjadi pipih

\section{METODELOGI PENELITIAN}

Penilitian ini dilaksanakan pada bulan Januari sampai dengan Februari 2017 di Laboratorium Perbengkelan Alat dan Mesin, Pertanian program studi Teknik Pertanian, Universitas Syiah Kuala

\section{Alat dan Bahan}

Peralatan yang digunakan pada perancangan alat pemipih biji melinjo yaitu berupa meteran, penggaris, gerinda, las, dan alat pendukung lainnya, Kemudian, peralatan yang digunakan pada pengujian alat pemipih melinjo semi mekanis dan pengujian tradisional adalah timbangan, wajan (belanga), pengaduk, telenan, pemukul, seng bertangkai, stopwatch, wajan (untuk emping), plastik, dan alat tulis.

Bahan yang digunakan pada penelitian ini yaitu besi kanal U, bantalan, besi assental, pipa besi, dan baut. Adapun bahan yang digunakan pada saat pengujian alat dan pengujian tradisional adalah biji melinjo, pelumas (minyak makan) dan pasir.

\section{Kriteria Desain}

Alat pemipih melinjo ini didesain dengan bahan dan material yang kuat serta mudah didapatkan dengan harga yang terjangkau. Desain alat dibuat sesederhana mungkin sehingga dapat dengan mudah dikembangkan dan digunakan oleh masyarakat khususnya pada pengrajin emping melinjo

\section{Pendekatan Fungsional dan Struktural}

\begin{tabular}{|l|l|l|l|}
\hline No & $\begin{array}{c}\text { Komponen } \\
\text { alat Pemipih }\end{array}$ & \multicolumn{1}{|c|}{ Fungsi } & \multicolumn{1}{c|}{ Bahan dan dimensi } \\
\hline 1. & Gagang & $\begin{array}{l}\text { Untuk menekan bebeban } \\
\text { pada saat alat dioperasikan }\end{array}$ & Besi assental dengan panjang besi $55 \mathrm{~cm}$ \\
\hline 2. & $\begin{array}{l}\text { Tiang depan } \\
\text { dan penyangga } \\
\text { keseragaman }\end{array}$ & $\begin{array}{l}\text { sebagai penyeimbang dan } \\
\text { keseragaman hasil pipihan }\end{array}$ & $\begin{array}{l}\text { Besi kana U 20 cm diameter } 8 \mathrm{~cm} \\
\text { Besi assental diameter 1,8 cm dengan } \\
\text { panjang 12 cm } \\
\text { Batang penyangga terbuat dari besi pipa } \\
\text { dengan panjang 17,5 cm berdiameter 2 cm }\end{array}$ \\
\hline 3. & Beben (Palu) & $\begin{array}{l}\text { Untuk memipihkan biji } \\
\text { melinjo yang masih utuh } \\
\text { menjadi lempengan. }\end{array}$ & $\begin{array}{l}\text { besi assental dengan diameter } 6,5 \mathrm{~cm} \\
\text { dengan ketebalan } 5 \mathrm{~cm}\end{array}$ \\
\hline 4. & $\begin{array}{l}\text { Rangkaian } \\
\text { tabung }\end{array}$ & $\begin{array}{l}\text { Untuk menyeimbangkan } \\
\text { rangkaian palu pemipih } \\
\text { (penekan), dan untuk } \\
\text { memudahkan pengeluaran } \\
\text { biji melinjo yang telah } \\
\text { dipipih }\end{array}$ & $\begin{array}{l}\text { Stainless plate dengan ukuran panjang 15 } \\
\text { cm dan lebar 7,5 cm dengan ketebalan 2 } \\
\text { mm } \\
\text { Rel besi kanal U dengan ukuran panjang 20 } \\
\text { cm dan lebar } 8 \mathrm{~cm} \\
\text { Besi pipa dengan ukuran panjang } 8 \mathrm{~cm} \text { dan } \\
\text { diameter 7,5 cm }\end{array}$ \\
\hline 5. & Lantai Alat & $\begin{array}{l}\text { Untuk mengikat bagian- } \\
\text { bagian yang lain seperti } \\
\text { bagian tabung dan penyangga } \\
\text { (penahan) }\end{array}$ & $\begin{array}{l}\text { Besi kanal U yang berukuran lebar besi } 8 \mathrm{~cm} \\
\text { dengan ukuran panjang potong } 50 \mathrm{~cm} \mathrm{dan} \\
\text { tinggi besi } 4 \mathrm{~cm} .\end{array}$ \\
\hline
\end{tabular}




\section{HASIL DAN PEMBAHASAN}

\section{Pengukuran Dimensi Emping Melinjo}

Pengukuran dimensi emping melinjo adalah salah satu acuan untuk merancang bangun alat pemipih. Setelah dilakukan pengukuran, emping dengan kualitas yang bagus adalah emping yang masuk kedalam nilai Standar Nasional Indonesia (SNI), nilai ketebalan yang masuk kedalam SNI yaitu 0,5-1,5 mm. Pengukuran dimensi emping melinjo dilakukan dengan 3 kali, ulangan setiap satu kali ulangan satu keping emping melinjo, Muharfiza (2014).

Tabel 1. Pengukuran Dimensi Emping Melinjo

\begin{tabular}{ccc}
\hline Sampel & $\begin{array}{c}\text { Diameter } \\
\text { Emping }(\mathbf{c m})\end{array}$ & $\begin{array}{c}\text { Ketebalan Emping } \\
(\mathbf{m m})\end{array}$ \\
\hline S1 & 3,70 & 0,48 \\
S2 & 4,01 & 0,56 \\
S3 & 3,62 & 0,62 \\
Total & $\mathbf{1 1 , 3 3}$ & $\mathbf{1 , 6 6}$ \\
Rata-rata & $\mathbf{3 , 7 7}$ & $\mathbf{0 , 5 5}$ \\
\hline
\end{tabular}

Sumber. Data diolah, 2017

\section{Alat Pemipih Biji Melinjo Hasil Rancangan}

Menurut Darmawan (2004), perancangan dan pembuatan produk adalah dua kegiatan yang sangat penting. Artinya, rancangan hasil kerja perancang menjadi tidak berguna jika rancangan tidak direalisasikan menjadi suatu produk yang berguna. Dan begitu juga sebaliknya, pembuatan tidak dapat merealisikan suatu produk tanpa terlbih dahulu ada sketsa gambar atau rancangan awal. Mekanisme kerja alat pemipih yang didesain masih dalam konsep kerja manual dengan bantuan gerak utama menggunakan tenaga manusia.

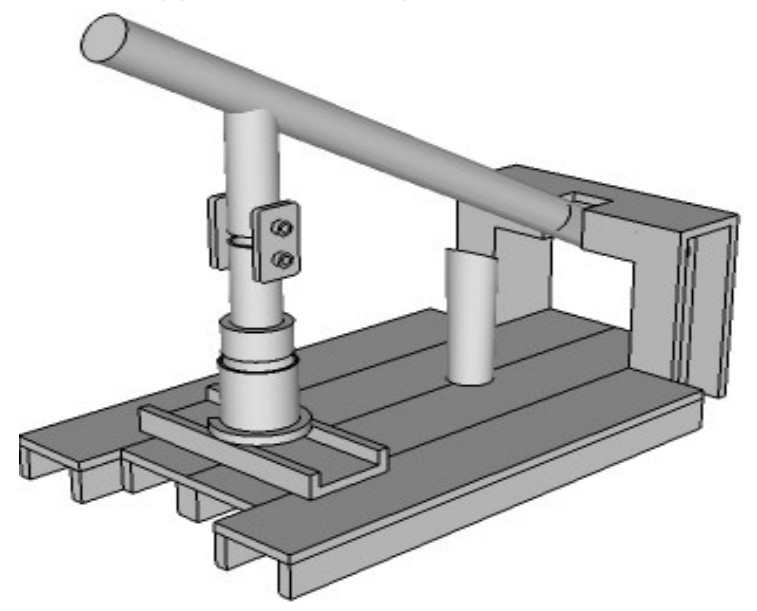

Gambar 1. Alat pemipih biji melinjo

\section{Uji Kinerja Alat Pemipih melinjo}

Menurut Richey 1994, suatu rancangan akan dikatakan berhasil dengan baik setelah dilakukan pengujian kerja dan hasil akhir dari kerja mesin akan menentukan hasil produk yang sesuai dengan keperluanya. Untuk alat pemipih biji melinjo pengujian yang dilakukan yaitu uji kapasitas kerja alat, selanjutnya pengujian ini dilakukan dengan 3 kali pengulangan, setiap satu 
kali pengulangan menggunakan 5 biji melinjo dengan berat awal biji melinjo yang berbeda dan setelah dirata-ratakan berat melinjo 8,105 gram.

\section{Perbandingan Kerja}

Perbandingan kapasitas kerja adalah perbandingan hasil olahan menggunakan alat semi mekanis hasil rancangan dengan pemipih secara tradisional.

\section{Kapasitas Kerja}

Tabel 2. Perbandingan kapasitas kerja menggunakan alat dan tradisional

\begin{tabular}{ccccccc}
\hline sampel & \multicolumn{2}{c}{ berat awal (gr) } & \multicolumn{2}{c}{ waktu (menit) } & \multicolumn{2}{c}{ kapasitas kerja alat (gr/menit) } \\
\cline { 2 - 7 } & tradisional & alat & tradisional & alat & tradisional & alat \\
\hline $\mathbf{s 1}$ & 7,916 & 8,208 & 1,02 & 0,54 & 7,760 & 15,2 \\
$\mathbf{s 2}$ & 8,388 & 8,273 & 1,04 & 0,51 & 8,065 & 16,221 \\
s3 & 8,096 & 7,834 & 1,08 & 0,56 & 7,496 & 13,989 \\
Total & $\mathbf{2 4 , 3 7 5}$ & $\mathbf{2 4 , 3 1 5}$ & $\mathbf{3 , 1 4}$ & $\mathbf{1 , 6 1}$ & $\mathbf{2 3 , 3 2 2}$ & $\mathbf{4 5 , 4 1 0}$ \\
rata-rata & $\mathbf{8 , 1 3 3}$ & $\mathbf{8 , 1 0 5}$ & $\mathbf{1 , 0 4}$ & $\mathbf{0 , 5 3}$ & $\mathbf{7 , 8 2 0}$ & $\mathbf{1 5 , 2 9 2}$ \\
\hline
\end{tabular}

Tabel 3. Perabandingan kapasitas kerja alat dengan tradisional Kg/jam

\begin{tabular}{ccccccc}
\hline sampel & \multicolumn{2}{c}{ berat awal $(\mathbf{K g})$} & \multicolumn{2}{c}{ waktu (jam) } & \multicolumn{2}{c}{ kapasitas kerja alat (Kg/jam) } \\
\cline { 2 - 7 } & tradisional & alat & tradisional & alat & tradisional & alat \\
\hline s1 & 0,0079 & 0,0082 & 0,017 & 0,009 & 0,464 & 0,911 \\
s2 & 0,0083 & 0,0082 & 0,017 & 0,008 & 0,488 & 1,025 \\
s3 & 0,0080 & 0,0078 & 0,018 & 0,009 & 0,444 & 0,866 \\
Total & $\mathbf{0 , 0 2 4 2}$ & $\mathbf{0 , 0 2 4 2}$ & $\mathbf{0 , 0 5 2}$ & $\mathbf{0 , 0 2 6}$ & $\mathbf{1 , 3 9 7}$ & $\mathbf{2 , 8 0 2}$ \\
rata-rata & $\mathbf{0 , 0 0 8 0}$ & $\mathbf{0 , 0 0 8 0}$ & $\mathbf{0 , 0 1 7}$ & $\mathbf{0 , 0 0 8}$ & $\mathbf{0 , 4 6 5}$ & $\mathbf{0 , 9 3 4}$ \\
\hline
\end{tabular}

Sumber. Data diolah 2017

Tabel 2 dan 3, menunjukkan perbedaan waktu rata-rata pemipih biji melinjo untuk pemipih tradisional dengan pemipih menggunakan alat. Waktu rata-rata untuk pemipih biji melinjo tradisional yaitu 1,04 menit $(0,017 \mathrm{jam})$ dengan kapasitas kerja tradisional 7,820 gram $(0,465$ $\mathrm{Kg})$. Untuk pemipih menggunakan alat adalah 0,53 menit (0,008 jam) dengan kapasitas 15,292 gram $(0,934 \mathrm{~kg})$. Perbedaan waktu kerja dapat mengakibatkan dengan hasil olahan atau hasil produk. Penyebab keterlambatan waktu pengolahan diakibatkan oleh faktor ketergangguan saat memukul biji melinjo sehingga pemukulan biji melinjo tidak sesuai dengan yang diharapkan 


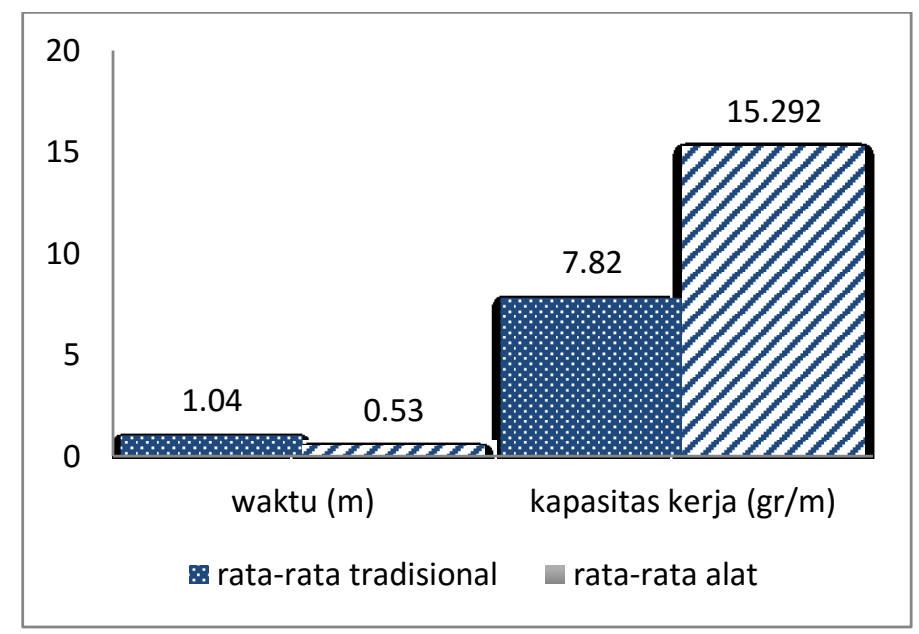

Gambar 2. Perbandingan kapasitas kerja gr/menit

Dari grafik diatas menunjukkan hasil perbandingan kapasitas kerja pemipih biji melinjo secara tradisional dengan pemipih menggunakan alat. Waktu rata-rata yang didapatkan untuk pemipih secara tradisional adalah 1,04 menit untuk 5 biji melinjo dengan berat rata-rata 8.133 gram. Sehingga kapasitas kerja pemipih biji melinjo tradisional menghasilkan emping dengan rata-rata sebayak 7,820 gram $/$ menit $(0,465 \mathrm{~kg} / \mathrm{jam})$. Sedangkan pemipih biji melinjo dengan menggunakan alat hasil rancangan didapatkan waktu rata-rata pemipih 0.53 menit untuk memipih 5 biji melinjo dengan berat rata-rata 8,105 gram. Sehingga kapasitas pemipih dengan meggunakan alat menghasilkan emping dengan rata-rata sebayak 15.292 gram/menit $(0,934$ $\mathrm{kg} / \mathrm{jam})$. Hasil proses pemipih biji melinjo menggunakan alat lebih efisien dan lebih cepat dibandingkan dengan pemipih tradisional.

\section{Keseragaman Hasil}

Tabel 4. Keseragaman hasil pemipih

\begin{tabular}{ccccc}
\hline \multirow{2}{*}{ sampel } & \multicolumn{2}{c}{ Ketebalan $(\mathbf{m m})$} & \multicolumn{2}{c}{ Diameter $(\mathbf{c m})$} \\
\cline { 2 - 5 } & Tradisional & Alat & tradisional & Alat \\
\hline $\mathbf{s 1}$ & 0,91 & 0,67 & 3,36 & 3,67 \\
$\mathbf{s 2}$ & 0,89 & 0,69 & 3,49 & 3,62 \\
$\mathbf{s 3}$ & 1,05 & 0,82 & 3,52 & 3,67 \\
total & $\mathbf{2 , 8 5}$ & $\mathbf{2 , 1 8}$ & $\mathbf{1 0 , 3 7}$ & $\mathbf{1 0 , 9 6}$ \\
rata-rata & $\mathbf{0 , 9 5}$ & $\mathbf{0 , 7 2}$ & $\mathbf{3 , 4 5}$ & $\mathbf{3 , 6 4}$ \\
\hline
\end{tabular}

Sumber. Data Diolah 2017.

Dari tabel 4 hasil ketebalan yang lebih pipih terdapat pada alat rancangan dengan nilai ketebalan rata-rata $0,72 \mathrm{~mm}$ sedangkan pada alat tradisional nilai rata-rata ketebalan lebih tinggi daibandingkan dengan alat rancangan yaitu $0,92 \mathrm{~mm}$. Untuk diameter emping melinjo pada alat rancagan didapatkan nilai $3,64 \mathrm{~cm}$ dan pada alat tradisional dengan nilai $3,45 \mathrm{~cm}$. 


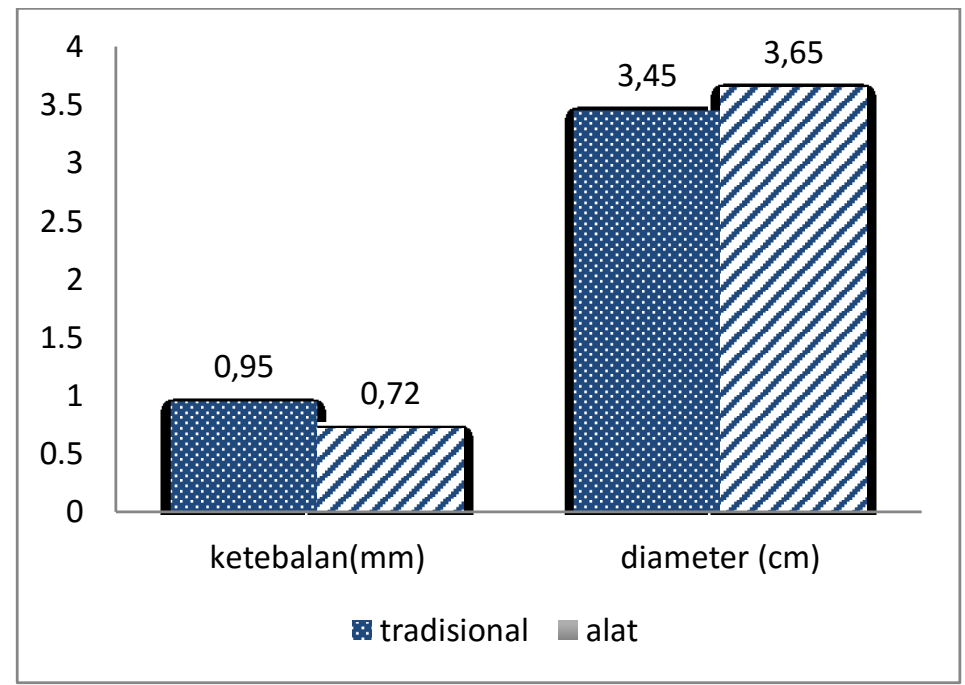

Gambar 3. Perbandingan kerseragaman hasil pemipih biji melinjo

Untuk hasil keseragaman ketebalan dengan menggunakan alat tradisional didapatkan nilai rata-rata $0,95 \mathrm{~mm}$ dan untuk ketebalan dengan menggunakan alat rancangan dengan ratarata $0,72 \mathrm{~mm}$. Selanjuntnya untuk nilai keseragaman diameter emping melinjo yang telah terpipih yaitu untuk pemipih dengan menggunakan alat tradisional didapatkan nilai rata-rata $3,45 \mathrm{~cm}$ dan mengunakan alat $3.64 \mathrm{~cm}$. Perbedaan hasil pemipih diakibatkan oleh tidak merata pada proses pemukulan biji melinjo sehingga hasil yang didapatkan akan berbeda

\section{Persentase Kehilangan Hasil}

Tabel 4. Perbandingan Persentase kehilangan hasil pemipih biji melinjo

\begin{tabular}{ccccccc}
\hline sampel & \multicolumn{2}{c}{ berat awal (gr) } & \multicolumn{2}{c}{ berat akhir $($ gr) } & \multicolumn{2}{c}{ kehilangan \% } \\
\cline { 2 - 7 } & tradisional & alat & Tradisional & alat & Tradisional & Alat \\
\hline s1 & 7,916 & 8,208 & 5,021 & 5,044 & 36,57 & $\mathbf{3 8 , 5 4}$ \\
s2 & 8,388 & 8,273 & 4,914 & 4,931 & 41,41 & $\mathbf{4 0 , 3 9}$ \\
s3 & 8,096 & 7,834 & 4,855 & 4,757 & 40,03 & $\mathbf{3 9 , 2 7}$ \\
rata- & $\mathbf{8 , 1 3 3}$ & $\mathbf{8 , 1 0 5}$ & $\mathbf{4 , 9 3 0}$ & $\mathbf{4 , 9 1 0}$ & $\mathbf{3 9 , 3 8}$ & $\mathbf{3 9 , 4 1}$ \\
rata & & & & & & \\
\hline
\end{tabular}

Sumber. Data Diolah 2017.

Pemipih biji melinjo secara tradisional kehilangan hasil yang telah dirata-ratakan adalah sebesar $39.38 \%$ dari berat awal melinjo yang telah diratakan 8.133 gram dan berat akhir 4.913 gram. Untuk kehilangan hasil pemipih dari penggunaan alat hasil rancangan adalah sebesar $39.41 \%$ dengan berat awal yang telah diratakan 8.105 gram dan berat akhir 4.913 gram. 


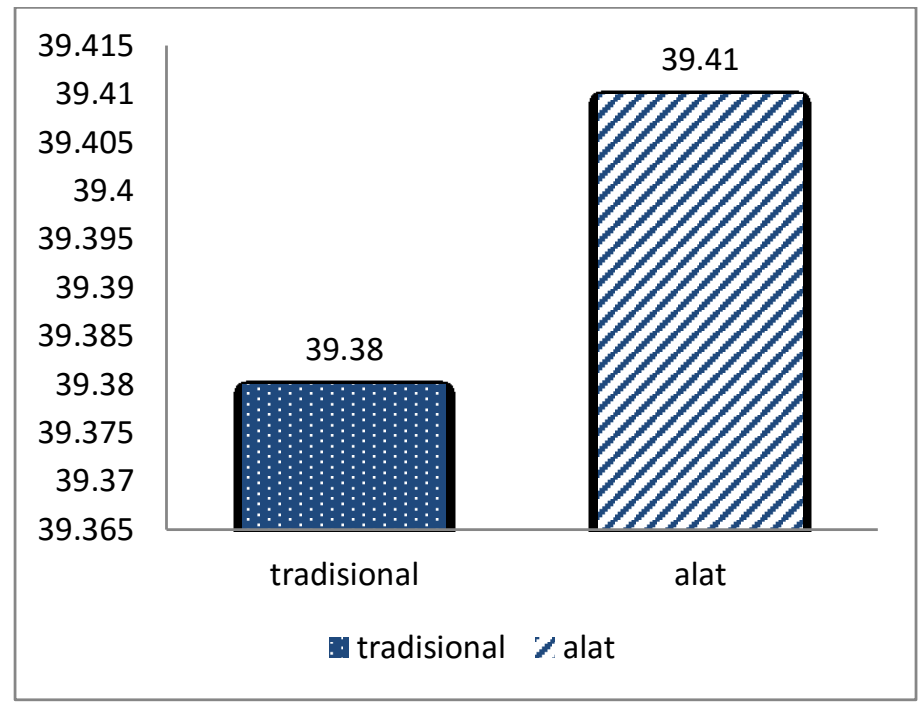

Gambar 3. Perbandingan hasil kehilangan pemipih biji melinjo

ari gambar 3 menunjukkan hasil kehilangan pada pemipih tradisional sebesar 39,38 \% dengan berat awal yang telah dirata-ratakan 8.133 gram, dan pada pengujian dengan menggunakan alat rancangan didapatkan persentase kehilangan sebesar 39,41\% dengan berat awal yang telah dirata-ratakan 8,105 gram. Dari pengujian yang dilakukan diantara pemipih biji melinjo tradisional dan pemipih hasil racangan terdapat kehilangan. Untuk kehilangan pada pemipih biji melinjo merupakan kehilangan kadar air sehingga berat awal menurun dan menjadi berat akhir yang ringan dengan emping telah dikeringkan.

\section{KESIMPULAN DAN SARAN}

Dari pengujian pemipih biji melinjo efisiensi waktu terdapat pada alat rancangan yang dapat memproduksi emping melinjo 15,292 gram dengan waktu 54 detik sedangkan pada pemipih biji melinjo tradisional didapatkan hasil produk 7,820 gram dengan waktu 1 menit 4 detik.

Penelitian lebih lanjut dapat dilakukan modifikasi pada gagang tuas penekan dan tiang rangka palu, hingga mempertimbangkan nilai ergonomikannya.

\section{DAFTAR PUSTAKA}

Badan Pusat Statistik, 2014, Pidie Dalam Angka, BPS, Kabupaten Pidie

Daramawan. 2013. Analisis Perhitungan Putaran Roll Pemipih Emping Jagung Dengan Kapasitas $100 \mathrm{Kg} / \mathrm{Jam}$. Universitas Wijaya Putra. Surabaya.

Muharfiza. 2014. Karakteristik Fisikokimia Kerupuk Melinjo Sebagai Upaya Diversivekasi Produk Olahan Melinjo. Balai Pengkajian Teknologi Pertanian Banten.

Richey 1994. Perancangan Mesin dan Pengembangan Peralatan Pertanian. Depatemen Teknik Mesin. Yogyakarta 